\title{
2
}

\section{Transitions and Transformations: The Making of Department Chairs}

\author{
Irene W. D. Hecht \\ American Council on Education \\ Center for Institutional and International Initiatives
}

When we talk about a need for leadership in higher education, we are in fact demanding that chairs be leaders. Is there then another level of transition that is required today of those who become chairs? Is task mastery a guarantee of being a leader? If there are other adaptations needed, what might they be? That is the focus of this exploration. This chapter examines the theory behind leadership and applies to it models that are aligned with the leadership skills needed for successful chair leadership. This article specifically addresses the role of faculty developers in supporting department chairs in their roles as institutional leaders and visionaries.

\section{INTRODUCTION}

No one would question that there is an important shift in responsiWility for the person who moves from being a faculty member to being a department chair. In fact, anyone contemplating that transition will find valuable two descriptions of the process, one offered by John Bennett (1983), the other by Walter H. Gmelch (1993). After reviewing those two astute snapshots of the transition process, my purpose will be to explore yet one more layer, asking the question: wherein lies the transition or transformation into a leader? My premise is that mastering tasks does not ipso facto attest to the transmutation into a leader. That process is embodied in important changes in perspective combined with the ability of managing important adjustments in human relationships.

Referring to department chairs as leaders does not always seem apt terminology. Within institutions at the level of central administration, there is still an overhang of the concept of chairs being the information 
conduit between administration and faculty. Deans want to be secure in the assumption that they are providing chairs with complete information and that in turn chairs are delivering clear messages with implicit agendas from central administration. And they rely on chairs to be effective in implementing institutional decisions. As for chairs, particularly new chairs, we know from questionnaires administered to participants in the America Council on Education's national workshops for chairs that they most frequently describe their role as that of facilitator for and supporter of their faculty (Hecht, 1999).

As with any caricature, both pictures-administrative agent or faculty-supporter is simplistic. However, conversations with chairs also indicate that the attitudes embedded in the caricature still retain validity. Meanwhile, the issues being faced by higher education institutionschanges in pedagogy; the distance learning revolution; the teaching-learning revolution; issues of productivity; the reconfiguration of faculty work conditions, including the addition of nontraditional and part-time faculty-are requiring visionary leadership and deft management. And unlike the bricks and mortar phase of campus building in the 1960s, these issues have to be solved if not exclusively at the department level, at least with the active engagement of department faculty. Thus, when we talk about a need for leadership in higher education, we are in fact demanding that chairs be leaders. Is there then another level of transition that is required today of those who become chairs? Is task mastery a guarantee of being a leader? If there are other adaptations needed, what might they be? That is the focus of this exploration.

\section{Two Models}

\section{John Bennett: A Transition Model}

The first transition model we have is that offered by John Bennett in 1983. Bennett suggested that there were three major transformations that would face anyone upon becoming a department chair. One was the transition from specialist to generalist. As academicians we are trained to be expert in what may be a very restricted and even esoteric area of knowledge. Upon becoming a department chair, the incumbent needs to be equally interested in the range of specialties represented by the total faculty of the department. The second transition Bennett suggests is moving from being an individualist to being a person running a collective. That transition parallels the move from specialist to generalist. As a faculty member, one is responsible for one's individual actions and deci- 
sions; as a chair one is responsible for decisions that affect other individuals. But note that Bennett goes beyond suggesting that the chair is responsible for other individuals to being responsible for the combined work of the faculty as a group. This is an important point because it suggests a shift from serial, one-on-one relations with various individuals to the ability to create a unified purpose among individuals.

The last transition Bennett points to is the refocusing of loyalty from one's discipline to the institution. This is perhaps Bennett's most challenging observation. Academic training is so discipline-focused that it is more natural to think that what a chair needs to do is see the discipline within the context of the institution. Bennett, however, pushes beyond that point to suggest that it may be necessary to set the disciplinary focus to one side and look at the needs and goals of the institution independent of department interests. That is certainly a challenging standard to set before any chair.

\section{Walter H. Gmelch: From Professor to Chair}

The second model is one which $G$ melch has presented on a number of occasions at the American Council on Education workshops for department/division chairs and deans. The model also appears in his text Leadership Skills for Department Chairs (Gmelch, 1993). The Gmelch model identifies a series of what one might call lifestyle changes when one becomes a chair. The once solitary life becomes a socially oriented one: chairs must now focus attention on the needs and wants of others. Scholarship is often a chair's major sacrifice as $s /$ he writes fewer manuscripts and instead chums out memoranda (or today, email). The stable, rather predictable life of a faculty member becomes the mobile, unpredictable life of a chair. Although new chairs are less apt to perceive the transition from austerity to prosperity, that, too, is a lifestyle change. In some departments, there is a physical aspect to that change if the position of chair comes with larger office space. It is unusual if the position does not bring the chair greater access to secretarial and student-aid assistance. There is also the "prosperity" of being able to call upon college/university staff to provide information and support.

Another transformation is from client to custodian. As a faculty member, one is in the position of asking for support up the line. As chair, one becomes the custodian of those requests, and in fact the chair may influence the fate of those client requests. On the other hand, there is a loss of individual power as one finds that instead of professing to one's colleagues, one needs to devote hours to persuading them of the need to 
FIGURE 2.1

\section{The Transformation from Professor to Chair}

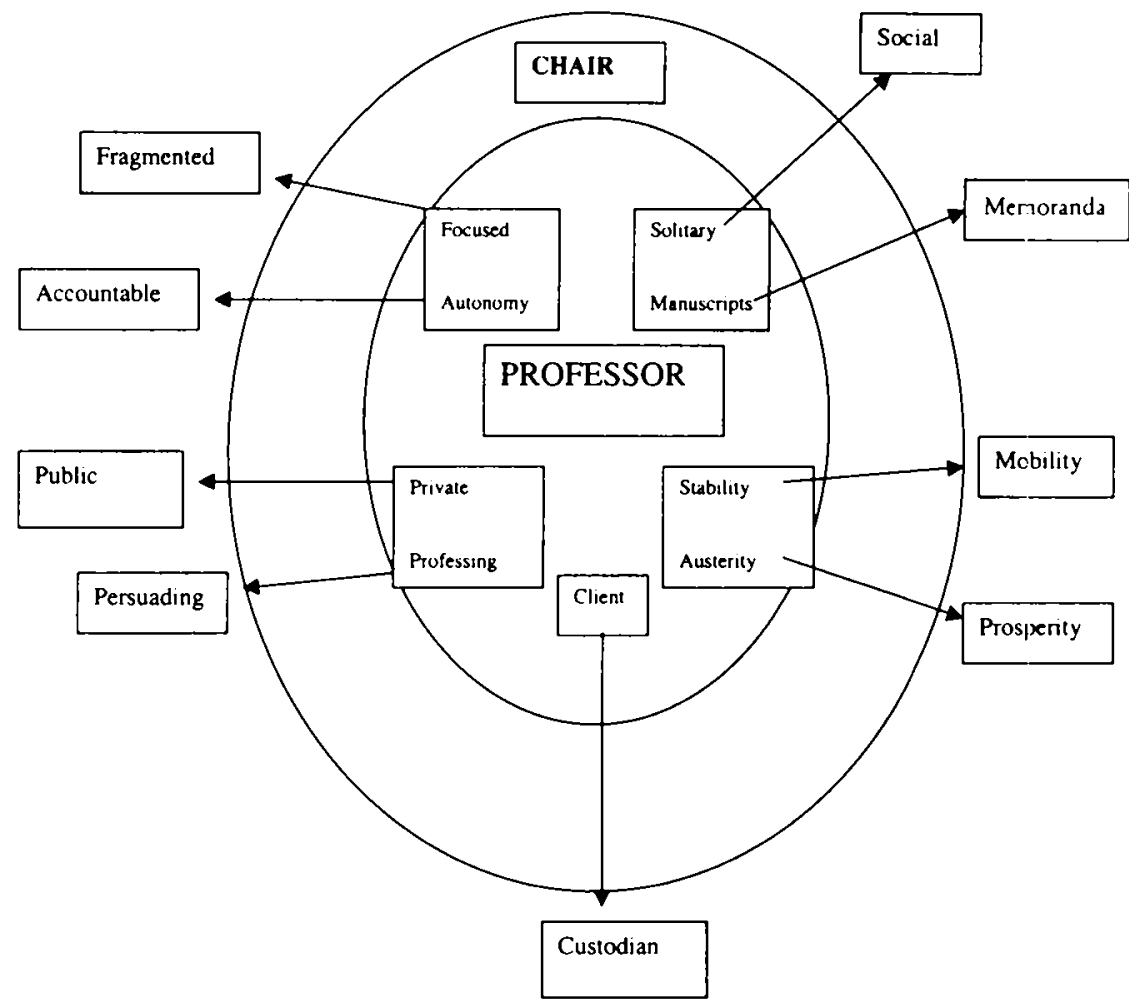

adopt a particular (rational) policy or take on (necessary) implementation tasks. And there is a loss of privacy as one becomes a public person. As one of the regular ACE presenters, Mary Lou Higgerson, puts it, as chair "you are never off duty." In small town settings, particularly, that can be a burden. Chairs are also burdened with the need to be accountable rather than autonomous. Distressing today is the range of audiences to which one finds oneself accountable! Lastly, chairs have to adapt to a life where focus is fragmented, and time is cut into minute slices. Attention may need to shift from working with a faculty member who has a home crisis, to the secretary whose computer has broken down, to the student who needs a waiver, and the dean who is desperate for your section of a board report, to say nothing of the random, unannounced visits, requests, admonitions enlivened by protests and ultimata that blow all one's carefully laid time-management strategies to the winds. 
The transitions and transformations described by Bennett and $\mathrm{Gmeich}$ are real. All chairs experience them with varying degrees of comfort or distress. But is there yet another dimension? Is there anything different about approaching the tasks enumerated as a leader rather than a manager? I am using the term "manager" to indicate the performance of designated tasks that are the responsibility of a chair. Is there something more than the performance of the required tasks that differentiates the leader? That is the issue I will now explore.

\section{The Chair as Academic Leader}

There is a familiar adage which says "Where you stand depends upon where you sit." Like all aphorisms, it both embodies a commonsense truth while simultaneously ignoring the complexity of reality. The truth in the statement lies in the acknowledgment that specific jobs or positions or roles carry with them recognized obligations. These exist independent of the particular person inserted into that position. Furthermore, that obligation is acknowledged both by the responsible person and the general citizen, player, participant, etc. who forms the other half of the equation. That pattern can be extrapolated across an infinite array of human relationships from parent and child, to policeman and citizen, boss and employee, professor and student. Each set has a recognized pattern of relationships of which the parties are aware. As long as the parties to the definition respect the rules, relationships remain workable and, ideally, can be highly productive and creative. If either side waffles on the basic understandings, tensions develop that can undermine the productivity of a relationship and, at worst, can create social breakdown and even armed confrontation.

However, this is only the surface layer of the aphorism which suffers from two serious limitations. Its first oversimplification is that it assumes that the parties are located indefinitely in particular defined positions. But as we all know, throughout life our positions change. Children grow up and themselves become parents. The citizen stopped by the policeman may be the proprietor of a business with dozens of employees. The boss may be afflicted with a serious illness and become a dependent patient. The student will one day become an expert in something unfamiliar to current professors. Time pushes us continually into new roles. That being the case, we are continually making transitions to new identities.

The second limitation is the unspoken assumption that knowledge lies within the position and that as soon as someone takes on a positional 
responsibility, changes in behavior will take place automatically. There is certainly a measure of truth in that conviction. The clearer the obligations of a position, the more likely a new incumbent will pick up the appropriate behaviors. But if the positional identity is itself ambiguous, the incumbent will have much more difficulty in adapting. That is in fact the case with the role of department chair. It is a position boasting a closet-full of contradictions. Chairs remain faculty members. So, they are still subject to the same institutional requirements imposed on all other faculty. With rare exception, they continue to teach, even if with reduced load. They continue to work physically in the same confines as when they were faculty only (though in some large departments the chair may move to more spacious quarters). They have review obligations for their faculty colleagues, but those review powers are exercised within informal bonds of friendship and association that can be difficult to ignore. Institutional structures and mores add to the ambiguity. Our colleges and universities persist in using command pyramids to depict their operations. In that model, chairs reside at the bottom of the pyramid as recipients of information, exhortations, and requests from the middle and upper reaches of the pyramid. And yet current circumstance has awakened deans and provosts of the need for proactive leadership at the department level-leadership that needs to be integrated with the larger goals of the institution.

If leadership is now required from department chairs, it must be acknowledged that there is much in current practice, customs, and conceptual vision that stands in the way. At the same time, the need for leadership at that level of the institution is now compelling. What adjustments may chairs need to make if they are to answer that institutional call for leadership? There are three aspects of the chair role that chairs themselves will need to adjust. One is chairs' understanding of their roles and responsibilities, the second is perspective on time, and third is a recalibration of human relationships. In addition, two adjustments will be needed at the institutional level. First, institutions will need to revamp their view of chairs and acknowledge their leadership contribution, and second, the dialog between chairs and deans will need to be rewritten.

\section{Roles and Responsibilities of Chairs}

Gaining the positional title is the easy first step. For department chairs, the responsibility is often thrust upon them. Perhaps the previous chair has had enough and steps down. Or a long-sitting chair decides to retire 
from faculty life. Or the current chair is ready for a sabbatical. Or maybe the department has defined terms of tenure, and someone else must take up the reins. Or perhaps the would-be chair has seen an opportunity to help the department and feels ready to test a new role. A little judicious lobbying may then put the individual in line to be offered the position. Somewhere in the process there will be the ego boost. Either faculty colleagues will elect you; or they will lobby you to take the position; or the dean may approach you soliciting your assistance. However it happens, for a brief moment new chairs will feel wanted and appreciated. It is even possible to feel a bit of a hero for stepping in where no one else wished to tread.

But it is foolish to expect the moment of appointment euphoria to last very long. The descent into the details of department reality may come not only swiftly, but brutally. Whether it is the need to hire adjuncts for the next term, or the obligation to make a tough tenure recommendation, or the need to staunch a bleeding budget, new chairs can expect something to burst the bubble of innocence long before they are comfortable in the position.

Whatever the details of appointment, inherent ambiguity abounds. To whom are you responsible? Do you serve at the pleasure of a dean? The probability is that the dean will have played at least a symbolic role, a bit like the Pope anointing the Holy Roman Emperor in centuries past. It is more likely that the dean will have had more than a ceremonial role. In current practice the dean may in fact hold final control over chair appointments. That will likely be the case if the chair is recruited from outside the institution. On the other hand, chairs and deans know that no chair can operate without a decent level of support from the department faculty. Does that mean that faculty colleagues are the chair's main constituency? Faculty are very likely to make that assumption. Proximity of contact and commonality of interest may induce a chair to pursue responsibilities with the complimentary conviction that faculty colleagues are and should be the main focus for concern.

From the start, chairs find themselves operating in a murky landscape of either ill-defined or conflicting expectations. A natural response may then be to concentrate on the tangible tasks that must be managed and mastered. Even new chairs have a sense of what a number of those tasks will be. The challenge in this domain lies in getting a grasp of the total package of tasks and learning to organize their handling efficiently and in a timely manner. It may initially be bewildering, because these task lists are fed not only by departmental routines, but also by institutional 
requirements. During the first cycle, some of these tasks will certainly come up seemingly from nowhere with a deadline of yesterday.

Let us assume for a moment that as a new chair you are able to make the adjustment to juggling multiple tasks within the same time frame and that you have developed your own tricks and strategies for managing your time effectively. Does that make one a leader, or are there are other characteristics a leader will manifest even in the domain of task management? I suggest there are deeper layers. Task mastery alone will not lift a chair above the level of super clerk. To organize tasks into an effective sequence is best described as clerical-level management. And indeed, many chairs complain that the job is more suited to a super clerk than it is to the skills of a faculty member. What would transform a tedious sequence of tasks into work fit for a leader?

One bridge lies in the articulation of purpose. If tasks are performed by rote without supporting a larger purpose, task activity becomes boring, wasteful, a drain of energy, and a source of frustration. On the other hand, when tasks are carried out because there is an important purpose to be served, even routine activity becomes important. A chair who is effective as a leader will be adept at demonstrating the larger purpose of a tedious task. For example, faced by a state requirement to review productivity in the department, the chair has the choice of offering the task as an unnecessary activity mandated by someone over whom the department (and institution) has little controlling influence, or of explaining how completing this task externally required can be handled in such a way as to support department interests. For example, how can the department use the data gathered for an outside review to leverage the department's interests? Chairs will manifest themselves as leaders to the extent that they are able to transmute the tasks demanded of the department into tasks that will support the goals of the department. The key leadership role for chairs is grasping the larger picture, demonstrating the connection between external audiences and the department, and keeping the department aware of its own vision.

The ability to keep track of the larger purpose (which I believe to be critical to thinking as a leader) also can reduce pressure on chairs. For example, faculty review is a stressful task. Chairs may focus on that task only in those moments when institutional policy demands that they make judgments for retention, promotion, and tenure. As chairs become leaders, they will see the review process as the practical mechanism and final step in a process of building a topflight departmental faculty. The chair-leader sees the creation of an outstanding department as an unend- 
ing and continual process. It means encouraging the professional development of pretenure faculty, encouraging the teaching experiments of all faculty, recognizing the professional achievements of all members of the department, supporting a department culture of mutual support and collaborative achievement. With an important, comprehensive purpose in mind of building a quality department, the stress elicited by the need to make judgments about colleagues falls into a less threatening perspective. Reviews are the summative tool that follows all the formative work a chair has exerted throughout the academic year. If the formative work has been done with care and consistency, the summative last step should not embody surprises on either side.

\section{Time}

There is another facet of task completion that will distinguish the super clerk from the leader. In a leadership discussion with several chairs at an American Council on Education workshop, one participant offered this insight, "As a leader, I need to think about time in a different dimension." What this person meant was that he had found it important to think about decisions in a long rather than a short time frame. Any manager makes dozens of decisions in every workday. Part of being an efficient manager is being able to sift information rapidly and arrive at a conclusion (decision) quickly. There is even a measure of exhilaration and a sense of accomplishment in being able to make those decisions swiftly. But leadership is manifest when one can differentiate between those decisions which are simple or routine and those which have the potential of impact beyond the immediate moment. For example, a proposal from a faculty member for a sabbatical could be described as a routine request. Chairs and departments, however, are aware that any sabbatical leave affects the department curriculum, the graduation progress of students, the teaching loads of colleagues, etc. Hence, departments may have policies that require sabbatical requests to be filed by a specific date, with decisions being made in the context of all the requests and the collective impact on the department, curriculum, and enrolled students. The same may be true for any number of decisions. Decisions which grant a privilege to one member have implications for all members of the department. A learned leadership skill is the ability to place a single event or request into a longer time frame and broader context. The closest some people are able to come to a leadership frame of mind is to simply say "no" to any request, operating on the assumption that any decision will have consequences-and at best will create new problems and demand 
new energy. Unfortunately that reaction on the part of a so-called leader simply freezes an organization into a state of immobility.

A facet of the art of thinking in extended time is the ability to anticipate those unanticipated consequences. Unanticipated consequences are just that: unanticipated. In the early days of the automotive revolution, it did not require great genius to see that we would need paved as opposed to gravel roads and that we would need to have lots of fuel stations available for the care and feeding of the horseless carriage. But how many anticipated that the automobile would destroy air quality? Had we done so, would we have halted the development of the automobile? Or would we have worked harder at developing an electric car? And had we pursued the latter course, what unanticipated consequences would have followed that decision? Perhaps the best one can do is expect the unexpected. That at least permits a leader to see the unexpected as a part of the routine of leading.

However, for chairs, especially new chairs, the most stressful change they face is the sheer volume of tasks they are expected to execute. We know this from questionnaires administered at the American Council on Education chair workshops. The expanded task list which all chairs struggle with makes time-management seem like the key to peace and sanity. And there is no doubt that on becoming a chair the incumbent will need to organize time differently. Perhaps the most uncomfortable transition is reconciling oneself to the fact that you need to be as disciplined in the use of time as the weight-watcher needs to be with the ingestion of food. The fact that one's effort to control time will frequently be derailed by the ad hoc arrival of people and problems needing attention, only makes expert time-management more important. One of the luxuries that is denied chairs is that of simply "going with the flow." Chairs adopting that tactic will soon find themselves drowning in a river of uncompleted tasks which unfortunately will often affect the lives of others who will soon lose patience with free-form practices.

One of the prices of good time-management is a loss of spontaneity. It becomes imperative to remain conscious of time as a finite commodity-the only commodity that can never be replaced. The time spent talking to " $A$ " means time away from task " $C$ ". Time spent completing task " $G$ " means you could not attend to the needs of faculty member " $F$ ". Effective time-management means being constantly aware of anything to which you devote attention in terms of its importance in the context of the other tasks and people you know are clamoring for your attention. It means actively prioritizing each thing, request, problem, person that 
comes forward. Good time management even means prioritizing time for yourself and for a measure of spontaneous activity. It means building in time-buffers to deal with the unexpected!

\section{Human Relationships}

Perhaps the most shocking change for any department chair is the alteration that takes place in human relationships. A powerful plaint on the part of chairs concerns the shift that takes place in their relationships with department colleagues. This may be the greatest source of stress for new chairs. I have heard a variety of comments on this matter. Some chairs find themselves ostracized from their favorite lunch group. Graced with a positional title, those you thought were your "pals" are no longer comfortable having you sit with them as they grouse, laugh, chide about their daily routine. Chairs who persist in maintaining friendly contact with old friends are apt to find that they are fostering suspicion among the rest of the faculty. They may even find that the old friends are themselves uncomfortable with the old intimacy. John Bennett (1983) pinpointed this transition particularly well when he stated that in moving from a faculty position to that of chair, you move from being responsible for yourself as an individual to being responsible for the welfare of a group. As a chair you are responsible in equal measure for each and every member of the department and the exercise of that responsibility is more complex than it was 25 years ago. Departments are far less homogeneous than they were say in 1970. Even though the percentage of women faculty nowhere near parallels the percentage of women students in our institutions (which now exceeds 50\%), nor does the representation of racial and ethnic minorities. Nonetheless, most department are no longer exclusively white, male bastions. If, as chair, you come from the venerable WASP category you have the challenge of being the leader for faculty who are different from you and who may harbor rancor and suspicion about your ability to be evenhanded, to say nothing about your instincts for being supportive of those who are different. If you are a chair who is from either a racial or ethnic minority or a woman, you may be even more taxed as you work to be "fair" to all members of the department. You may have to buck unspoken convictions that you cannot be up to the task. Or if you attempt to lead in an unexpected direction or insist on using unfamiliar principles in decision-making, you may find yourself thwarted by passive-aggressive behavior, procrastination, or even open hostility.

Specific responses will certainly vary from department to department 
and from institution to institution and will be affected by past history of both the department and the institution. What you can expect is that you will no longer be treated as an ordinary colleague. There will be a measure of distance or formality that will be observed, if not on your side, certainly on the part of your colleagues. To buck that seismic shift will undermine your success as a leader. You can put this distancing down as one of the prices of positional leadership.

This change in relationships can be a source of great dismay and discomfort. What perhaps is left unsaid is the frightening prospect that one has lost all one's friends! Gone is the luxury of dropping down to a favorite colleague's office to unburden oneself of the day's distresses. This is true for one's personal anxieties and is categorically true for most worries you have about the department, particularly if those concerns focus on the performance of particular individuals. Knowing that this adjustment will need to take place can give you leverage on the problem. Realizing that collegial friendship within the department will be constricted, a new chair can be proactive in encouraging an alternative network of friends. Rather than seeing the leadership transition as one that is going to reduce one's social range, use the situation as a platform to expand the reach of friendship. Inside the institution other chairs may be a source for new friendships. Within the community, this can be an ideal moment to cultivate work-related contacts into friendships, or it may be a moment to build contacts around your personal interests and hobbies. One door may indeed be closed, but it may be the very moment to realize that the room has a number of unexplored portals that only need to be pushed open.

Professional relationships will also change between the chair and other players in the institution. Among those, none will be more important than the dean or provost to whom a chair reports. A chair who sees no other relationship to a dean than that of subordinate to superior will be severely constrained as a leader. Effective leadership in a chair does not mean being a prima donna who must have everything her way. Nor does it mean being a humble lackey following the master's orders. Leadership in a department chair means being proactive, having a shared vision with department colleagues, and connecting that departmental vision with the goals of the institution. It means being aware of the needs and stresses experienced by other leader-colleagues. In a recent chair/ dean workshop, I had the opportunity to hear a chair announce with some amazement that as a result of working together with deans, he had come to the realization that deans were people, too! That may seem 
remarkably naive, but I suspect that deans would be appalled to hear how often chairs do not see them as human at all. Deans and chairs need to put effort into creating a collegial level of discourse. After all, most institutional problems cannot be effectively ameliorated without a coordinated (and cooperative) effort by both deans and chairs. Here again is an instance where chairs can exert leadership in helping build linkages that support common goals. Leadership is denigrated when it is practiced as a sport of winner-take-all.

\section{InSTITUTIONAL AdJUSTMEnTs}

\section{Chair Leadership within the Institution}

If chairs are to become leaders rather than super clerks, chairs will need to think more broadly about their roles; they need to be disciplined in their use of time; and they need to be prepared to reorganize their personal associations with their faculty colleagues. But leadership takes place within a context, and the institution is that context. Working under current definitions of university structure, there are impediments to the acceptance of chairs as leaders. Unlike the position of dean, provost, or president which are positions that share a broad framework of responsibilities that range across all varieties of institutions, the position of chair lacks such clarity. The terminology itself is remarkable, ranging from chair to chairperson, to coordinator, to head to lead faculty. Even when the same term is used, do not expect the same principles of definition to apply. Institutions that are looking to chairs to be proactive leaders need to look at their terminology-and the assumptions that inhere to that terminology. Are their leadership expectations compatible with the title assigned? And chairs need to understand the institutional context as they endeavor to meet the leadership expectations of their departments.

\section{Chairs and Deans}

Lastly, the process of dialog between deans and chairs needs to be reformulated. In reviewing questionnaires from participants at the American Council on Education chair workshops, it is evident that chairs and deans usually meet with regularity. What I find interesting is that when asked who presides and who sets the agenda, the common response to both questions is: the dean. While that response does not reflect the dynamic of conversation at such meetings, it does suggest that in practice, it is the dean who forms the agenda and retains control of the dialog. There are examples of chairs who report either that chairs meet 
independently or who indicate that there is an elected chair who presides at chair/dean meetings. But those responses are the exception.

For chairs to exert their full potential as leaders, this process of dialog needs to change. Deans are not reluctant in stating that they cannot achieve their goals without the support of chairs. If such is the case, then deans need to engage chairs as partners in the discussion. It also means that deans need to foster a collegial discussion among chairs rather than fostering a position of rivalry between them. Institutions cannot afford the luxury of warfare between departments--one department's win being another department's loss. Deans need to help chairs find their points of common interest.

\section{Conclusion}

Functioning as a leader assumes specific adjustments in behavior. These adjustments are common to leaders in general. However, the transformation process is particularly fraught for those who become department chairs. This is true in part because of the ambiguities of the position and the lack of clarity about its scope at the institutional level. While new chairs are particularly concerned about task-mastery, the truth is that the attitudinal adjustments are the ones most important for chairs to make if they are to become effective leaders. One perspective that needs adjustment is that concerning tasks. Unless a chair intends to operate as super clerk, s/he must see tasks within the context of department and institutional goals. Routine tasks are important when they are carried out as part of broad goals. A second adjustment that makes for an effective leader is a revised understanding of time. Chairs feel overwhelmed by the scope of responsibility thrust upon them. Hence, managing time becomes a prime problem. A key step in mastering the time challenge is constantly to prioritize, making time for those things that truly matter and setting aside those that fall on a lower level of priority. The last and most trying adjustment is in human relationships, which will have to be handled more objectively than subjectively.

Chairs will not attain their maximum effectiveness as leaders without adjustments across the institutional context. Upper administration needs to define and make publicly explicit its expectations of chairs. Having done that, institutions must make the necessary adjustments to policy documents. However, the most important adjustments may be the behavioral ones that will be required of deans who need to find the means to include chairs individually and as a category in the leadership 
processes of the institution. For those who succeed, the payoff for our institutions will be high in terms of more effective leadership in meeting the challenges of an uncertain future.

\section{REFERENCES}

Bennett, J. (1983). Managing the academic department. Phoenix, AZ: Oryx.

Gmelch, W. H., \& Miskin, V. D. (1993). Leadership skills for department chairs. Bolton, MA: Anker.

Hecht, I. W. D. (1999, Fall). Transitions from faculty member to department chair. The Department Chair: A Newsletter for Academic Administrators, 10 (2), p. 5.

\section{Contact:}

Irene W. D. Hecht

Senior Associate

American Council on Education

Center for Institutional and International Initiatives

Washington, DC 20036

President

Higher Education Associates

3432 NE Schuyler St.

Portland, OR 97212

(503) 249-8392 (telephone and fax)

Email: d9ih@odin.cc.pdx.edu

Irene W. D. Hecht is a consultant to and a Senior Associate with the American Council on Education (ACE). Since 1992, Hecht has directed the ACE Department Leadership Program, applying her broad experience in both private and public higher education to lead the expansion of ACE's national seminar program for department chairs. In addition to her scholarly publications as an historian, Hecht has written for the The Department Chair newsletter and contributed to the volume edited by Peter Seldin, Improving College Teaching. Her new book with Mary Lou Higgerson and Walter H. Gmelch, The Department Chair as Academic Leader, is available from Oryx Press. 